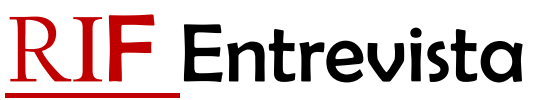

\section{Desafios e atualizações nas atividades da Comissão Nacional de Folclore}

\author{
Élmano Ricarte ${ }^{1}$ \\ Beatriz Lima de Paiva ${ }^{2}$ \\ Maria Erica de Oliveira Lima ${ }^{3}$
}

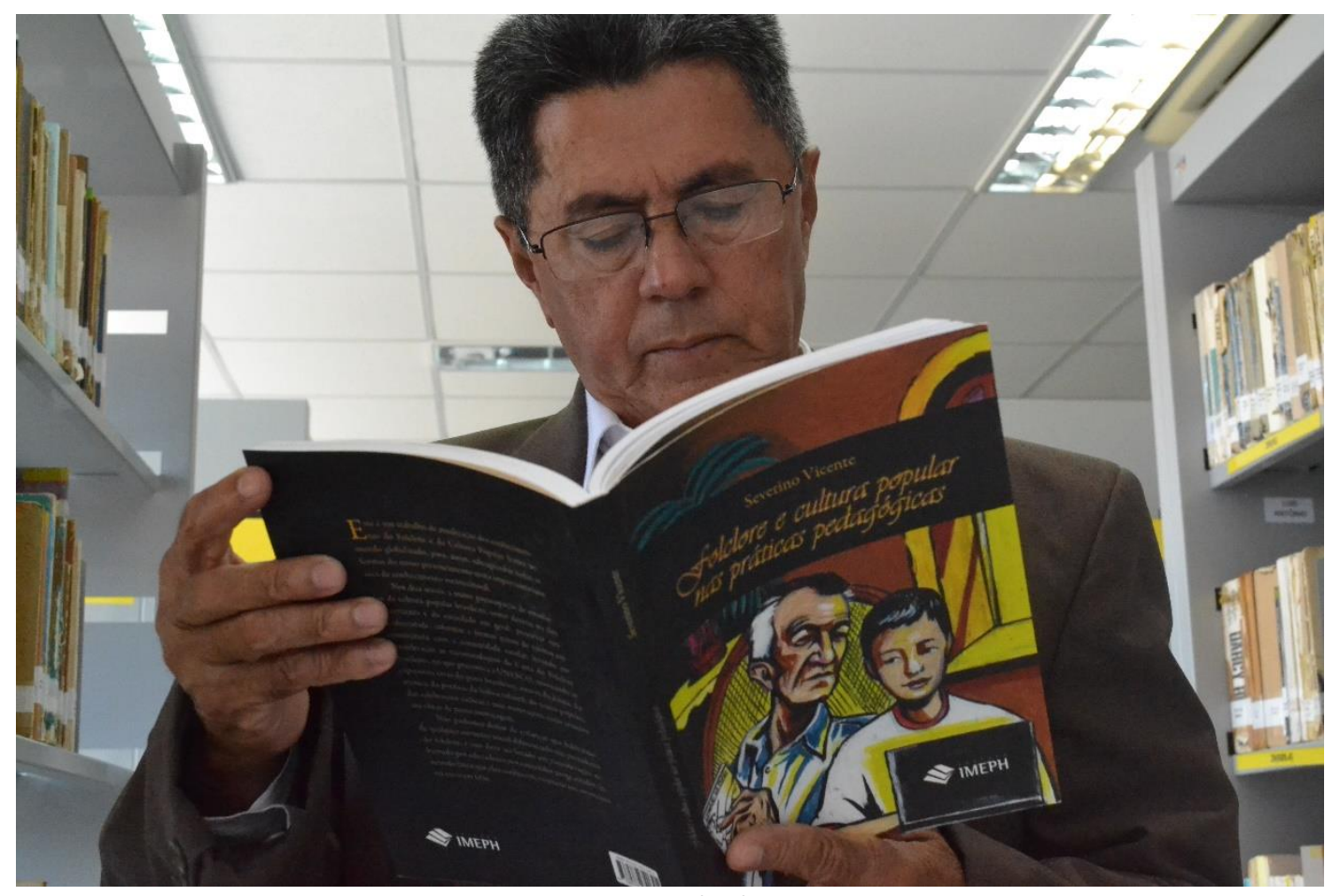

Foto: Beatriz Lima

“(...) muita gente diz: 'ah o folclore está fora de moda...', eu digo: 'não'!!! Fora de moda é quem não compreende as inserções de como o folclore está atuando hoje dentro de um novo contexto sociocultural".

Severino Vicente

\footnotetext{
${ }^{1}$ Doutorando em Ciências da Comunicação, Universidade Católica Portuguesa - UCP (Bolsista da CAPES). Graduado em Jornalismo e em Radialismo pela Universidade Federal do Rio Grande do Norte - UFRN (Brasil), com graduação sanduíche na UCP. Mestre na linha de Pesquisa de Produção de Sentido do Programa de Pós-graduação de Estudos da Mídia da UFRN. Investigador Júnior do Centro de Estudos de Comunicação e Cultura - CECC/UCP. Integrante do OBES - Observatório BOA-VENTURA de Estudos Sociais - CCHLA/UFRN, em convênio com a Universidade de Coimbra-Portugal. Membro da Rede de Estudos e Pesquisa em Folkcomunicação - Rede FOLKCOM.

${ }^{2}$ Formada em Comunicação Social, habilitação em Radialismo, do departamento de Comunicação Social, da Universidade Federal do Rio Grande do Norte. Participou da Iniciação Científica no projeto de pesquisa "As Manifestações Culturais em São Gonçalo do Amarante/RN no contexto da Epistemologia do Sul”.

3 Jornalista, mestre e doutora em Comunicação. Professora Associada do curso de Jornalismo e do Programa de Pós-graduação em Comunicação (UFC). Conselheira da Rede de Estudos e Pesquisa em Folkcomunicação.
} 


\section{RIF, Ponta Grossa/ PR Volume 15, Número 34, p.250-256, Janeiro/Junho 2017}

A obra Dicionário do Folclore Brasileiro, de Luís da Câmara Cascudo completou 60 anos em 2014. A Revista Internacional de Folkcomunicação realizou três entrevistas para recordar o aniversário desta bibliografia, cuja importância dar-se como uma referência sobre a cultura brasileira e global e é, além disso, uma das bases para a Folkcomunicação de Luiz Beltrão e os estudiosos deste pensamento. A terceira e última destas entrevistas é com Severino Vicente, presidente da Comissão Nacional do Folclore.

Severino Vicente conversou com a nossa equipe sobre os desafios de manter a Comissão Nacional do Folclore ativa pelo vasto território brasileiro. Além disso, nossa entrevista com esse pesquisador da cultura popular tratou das ferramentas disponíveis na internet e sua utilidade para a Comissão.

Apesar de ainda haver uma imagem de que as pesquisas relacionadas ao Folclore investigam o passado e a tradição, nossa entrevista com Severino Vicente revela que já há muitos estudiosos interessados em encontrar sintonia com os estudos mais recentes da Folkcomunicação no âmbito da internet.

Esta entrevista ocorreu em setembro de 2014, na cidade do Natal (estado do Rio Grande do Norte, Nordeste do Brasil), e contou com o apoio da Rede de Estudos e Pesquisa em Folkcomunicação - Rede FOLKCOM e do Laboratório de Comunicação, do Departamento de Comunicação Social - Universidade Federal do Rio Grande do Norte.

Neste momento, como está a situação da Comissão Nacional de Folclore? Como são organizados os eventos, qual é a agenda e as atividades que estão sendo realizadas?

Severino Vicente: a Comissão Nacional de Folclore hoje está vivendo um momento de abertura, porque ela passou durante muito tempo sob a presidência de grandes nomes, grandes pesquisadores da cultura popular e do folclore brasileiro. Portanto, na minha presidência, eu adotei algumas regras que acho que são normais nos dias de hoje. As transformações são muito rápidas e a gente tem que acompanhar esta dinâmica e a Comissão Nacional era criticada, porque diziam que nós ficávamos afastados do contexto sociocultural dos demais segmentos da cultura nacional, fechado entre nossas pesquisas e fechados entre os nossos livros. Hoje não, o presidente da Comissão Nacional está saindo para visitar festivais e encontros que não são programados pela própria comissão. Isto porque o Brasil é um país diverso e a Comissão Nacional deve acompanhar essa dinâmica da diversidade cultural 


\section{RIF, Ponta Grossa/ PR Volume 15, Número 34, p.250-256, Janeiro/Junho 2017}

brasileira em todos os seus aspectos possíveis. Isso faz com que a gente renove as conceituações, renove inclusive a Carta do Folclore Brasileiro, já que a última foi escrita em 1995. Nós queremos reescrever a outra agora no próximo Congresso Brasileiro de Folclore, porque as conceituações que foram dadas no passado - não vou dizer que estão superadas merecem reparos para que possam ser ajustadas dentro do novo contexto sociocultural brasileiro.

\section{Quais são os desafios de fazer parte dessa presidência?}

Severino: o desafio maior que eu enfrento é justamente que o Brasil é um continente! E não só... Eu sei que hoje a comunicação, a internet facilita muito, mas, muitas vezes, a internet não resolve e eu tenho que ir in loco resolver problemas e de comissões em estados distantes. Por exemplo, eu tenho que ir ao Rio de Janeiro, onde tudo começou, e eu não estou conseguindo resolver o problema da Comissão do Rio de Janeiro pela internet ou pelo telefone. Eu tenho que justamente fazer uma reunião in loco com todos os membros para ajustar as novas formas como eles trabalharam e saber o que foi que houve que eles estão se distanciando e não estão se associando ao centro do contexto de trabalho que exige a Comissão Nacional do Folclore. Mas a gente vai aos congressos mesmo que estes não sejam promovidos pela Comissão Nacional. E eu estou com seis a sete meses como presidente, já saí umas quatro ou cinco vezes para eventos culturais que não foram promovidos pela comissão. Nós queremos fazer essa integração dentro desse país diverso que é o Brasil.

\section{E qual a importância dos congressos para a Comissão de Folclore?}

Severino: Os congressos que a Comissão Nacional sempre realizou são verdadeiros espaços para que os estudiosos levem suas pesquisas, os seus trabalhos que eles fazem em suas comunidades. Há o resultado desses congressos em livros, publicações inclusive... São momentos muito ricos, deixam muito para o Brasil, contando ainda que a Comissão Nacional de Folclore tem o maior acervo de pesquisa de folclore e cultura popular do país. Nenhuma instituição tem o acervo que tem a Comissão, porque desde Renato Almeida, em 1951, quando houve o primeiro congresso até o último que houve agora em Florianópolis, todos esses congressos deixam um verdadeiro acervo de pesquisa, de estudos práticos e reais sobre a situação da cultura popular e do folclore brasileiro. 


\section{RIF, Ponta Grossa/ PR Volume 15, Número 34, p.250-256, Janeiro/Junho 2017}

\section{E isso tudo está disponível no site da Comissão?}

Severino: Muita coisa está e outras não estão, porque é muito material e a Comissão Nacional não tem dinheiro para fazer isso. Mas eu pretendo, em articulação com o Ministério da Cultura, fazer um trabalho para disponibilizar tudo isso no site, porque nem o congresso que houve aqui em Natal - que eu coordenei - não foi disponibilizado. Nós fizemos um congresso aqui em Natal, o décimo segundo, um dos mais ricos de conteúdo; na terra de Cascudo e tinha que ser assim.

\section{Além do Ministério da Cultura, quais são as outras parcerias que existem?}

Severino: Cada comissão tem a liberdade de fazer parcerias com seus respectivos estados. A Comissão Nacional é um órgão que faz todo esse trabalho de articulação com as comissões estaduais. Mas as comissões estão livres para fazerem suas articulações e muitas delas trabalham em parceria com os governos dos estados, com as prefeituras, com o SEBRAE. A Comissão não interfere na forma como as comissões estaduais trabalham. Nós apoiamos inclusive que elas usem a logo da Comissão Nacional para fazerem seus trabalhos com o apoio de qualquer segmento local.

\section{E como é que está a atuação dessas comissões em seus respectivos âmbitos?}

Severino: Há comissões dinâmicas. Eu não gostaria de citar quais as mais dinâmicas, porque eu causaria um problema com as que não acompanham essa dinamicidade, mas, devo dizer que existem umas 10 ou 12 comissões que têm um trabalho fantástico. Todos os dias eles trabalham, eles fazem eventos todos os meses, sobretudo no mês do folclore. Mas há outras comissões que não acompanham essa dinâmica de trabalho em relação ao folclore em seus respectivos estados, mas a gente não tem o que fazer, é assim. Existem aqueles mais dispostos, aqueles mais comprometidos... Nós temos hoje 25 comissões organizadas, isso é um trabalho gigante. Quando assumi, nós estávamos com 22 comissões e já conseguimos reestruturar cinco.

E qual é a relação prática que eles têm com cada um dos grupos folclóricos em seus respectivos locais? 


\section{RIF, Ponta Grossa/ PR Volume 15, Número 34, p.250-256, Janeiro/Junho 2017}

Severino: Eles fazem aquilo que Cascudo sempre recomendou: "quer estudar o folclore, quer conhecer o folclore? Vá às comunidades! Vá conversar com os mestres, vá conversar com o povo, vá conversar com os grupos!" e as pesquisas deles são sempre feitas nesse sentido, como nós fazemos aqui no Rio Grande do Norte. É um trabalho muito interessante, é um trabalho que exige disposição, é um trabalho que exige, sobretudo, compromisso. Se você não tiver compromisso, você não trabalha no folclore.

\section{Quais são as parcerias que o senhor tem desenvolvido atualmente com os pesquisadores em}

\section{Folkcomunicação?}

Severino: Eu sou amigo pessoal de Severino Lucena e de Osvaldo Trigueiro, da Paraíba, o presidente da Comissão Paraibana de Folclore, também meu amigo de trinta anos de estrada e de congressos. Então, nós conversamos muito e temos muitas parcerias. Foi justamente através de Osvaldo que eu cheguei até a Folkcomunicação. Ele disse: "olha, Severino, eu acho importante que você se aproxime desse setor porque a Folkcomunicação é uma ciência que cresce no Brasil e o folclore pode ganhar muito com isso e como também a Folkcomunicação pode ganhar com a aproximação da Comissão Nacional de Folclore". E foi aí que eu cheguei, viemos aqui, participamos da primeira Jornada de Folkcomunicação aqui em Natal (maio de 2014). A jornada foi organizada pela Rede Folkcom e pelo Programa de Pós-graduação em Estudos da Mídia, da Universidade Federal do Rio Grande do Norte, com apoio do Centro de Ciências Humanas, Letras e Artes. A primeira jornada de Folkcomunicação foi um sucesso! Ela aconteceu em concomitância em Recife e também na Paraíba, em Campina Grande.

\section{Atualmente, como é que tem visto a inserção de novos investigadores no âmbito do estudo} da cultura popular?

Severino: Eu fui agora ao Festival Internacional de Folclore, em Pirenópolis. Eu fiquei muito feliz pela grande quantidade de jovens de outros estados à procura de conhecer o presidente da Comissão Nacional de Folclore e saber qual a forma deles se aproximarem, como eles podem entrar na comissão. A melhor forma é a de se aproximarem das comissões estaduais, porque eles se aproximando das comissões estaduais, eles estão objetivamente na comissão

nacional e participarão do nosso congresso. Eu fiquei muito feliz porque muita gente diz: "ah o folclore está fora de moda...", eu digo: "não"!!! Fora de moda é quem não compreende as 


\section{RIF, Ponta Grossa/ PR Volume 15, Número 34, p.250-256, Janeiro/Junho 2017}

inserções de como o folclore está atuando hoje dentro de um novo contexto sociocultural. A juventude é o grande palco da Comissão Nacional e é com ela que eu vou trabalhar. É em busca dessa juventude não só brincante, mas estudiosa e pesquisadora, que a Comissão vai colocar o seu foco. Aqui, na terra de Cascudo - por incrível que pareça - "ninguém é bom profeta em sua terra", não é? Fora daqui a Comissão Nacional tem muito mais visibilidade do que no próprio estado. Mas, evidentemente, a gente vai abrindo os espaços, a gente vai procurando conversar, a gente procura se articular... É a primeira vez que a Comissão Nacional tem um potiguar na sua presidência. E uns reconhecem, outros não reconhecem, mas o nosso trabalho continua. $E$, além desses jovens, nesses últimos quatro ou cinco anos nós perdemos nomes que estão fazendo muita falta não só a Comissão Nacional de Folclore, mas também muita falta ao folclore brasileiro. Vamos começar com a professora doutora Neuma Fechine, da Paraíba. Esta mulher era fantástica! Eu a conheci pessoalmente. Não só inteligente, não só dedicada, não só comprometida com a cultura popular, mas era uma trabalhadora incansável. Perdemos o grande Altimar Pimentel, também da Paraíba, que eu tive a oportunidade de ir agora na sua cidade, em Cabedelo. Lá se comemora o "ano Altimar Pimentel". Foi uma homenagem muito grande com a presença da esposa dele. Perdemos o nosso Luís Antônio Barreto, que eu o chamo de "o filósofo do folclore brasileiro", um homem extraordinário. Perdemos também o nosso Roberto Benjamim, que vocês conhecem. Um pensador inteligente, sério, um pesquisador, incansável... Ele com os demais, estão fazendo muita falta não só à Comissão - quero repetir - mas aos estudiosos da Folkcom, porque Roberto também estudava Folkcomunciação. E também Luís Antônio Barreto tem as suas inserções para a Folkcomunicação, para a cultura e folclore brasileiro. E ainda o grande Ariano Suassuna. Esse foi o nosso "cavaleiro", o homem que saiu divulgando o Brasil, cantando o Brasil, era um poeta! Ele cantava e o que povo pensa, sente, diz, com aquele ar bem-humorado, não é? Participante de todos os palcos, cantando e defendendo o Brasil, defendendo a cultura do Brasil real.

Como é que estão os lançamentos do senhor? Agora vamos falar das suas produções. 0 senhor também tem um livro lançado sobre as questões pedagógicas do folclore, não é isso?

Severino: Esse livro eu fiz justamente para atender esta situação. É um trabalho de atualização dos conhecimentos do folclore e da cultura popular feita ao mundo globalizado, 


\section{RIF, Ponta Grossa/ PR Volume 15, Número 34, p.250-256, Janeiro/Junho 2017}

para assim, salvaguardar todas as formas dos nossos pertencimentos dessa importante área de conhecimento sociocultural. Eu fiz este livro com este objetivo, sendo um livro moderno, com conceituações atualizadas, que já foi lançado há uns três anos. O livro está esgotado e eu pretendo fazer uma reedição, acrescentar mais alguma coisa, porque um livro tem sempre o que acrescentar.

\section{Com essas perspectivas de preservação, a internet é uma ferramenta possível para a} Comissão?

Severino: Nós temos um site muito bom: http://comissaonacionaldefolclore.org.br. Para se aproximar mais do contexto das massas nós criamos uma página da Comissão Nacional no Facebook: https://www.facebook.com/comissaonacionaldefolclore. Se você acessar, você vai acompanhar todo o dia a dia da Comissão Nacional, tudo que acontece nos estados e só assim nós estaremos em consonância com toda a sociedade brasileira no que se relaciona à cultura popular, o nosso folclore. E a cultura popular também tem se integrado muito a essa questão da Internet, principalmente a partir de exemplos como Bode Gaiato (https://www.facebook.com/BodeGaiato), Suricate Seboso (https://www.facebook.com/suricateseboso/), e tantos outros que se multiplicam. 